\title{
EFFECT OF STERILIZATION USING GAMMA RADIATION ON THE PHYSICOCHEMICAL PROPERTIES OF GEL CONTAINING ALOE VERA POWDER
}

\author{
ARIF BUDIMAN \\ Department of Pharmaceutics and Pharmaceutical Technology, Faculty of Pharmacy, Universitas Padjadjaran, Jl. Raya Bandung Sumedang \\ Km 21, Indonesia \\ Email: arif.budiman@unpad.ac.id
}

Received: 11 Apr 2021, Revised and Accepted: 29 May 2021

\begin{abstract}
Objective: This study aims to prepare sterile gel containing aloe vera (AV) powder and evaluate its physicochemical properties after sterilization by gamma radiation.
\end{abstract}

Methods: The gel was prepared using carbomer as stabilizer, and sterilized by gamma radiation. The physical stability was evaluated including organoleptic, pH, viscosity and sterilization. Furthermore, malic acid concentration was determined as a marker compound contained in the gel.

Results: The gel was successfully prepared containing $20 \% \mathrm{AV}$ powder and $25 \%$ carbomer. The physical properties including organoleptic, pH and viscosity were not significantly changed after sterilization, and also stable even after 28 storage days. Meanwhile, malic acid concentration before and after sterilization were $47.2 \mathrm{mg} / \mathrm{ml}$ and $43.9 \mathrm{mg} / \mathrm{ml}$, respectively. This showed the physicochemical properties were not significantly different after sterilization.

Conclusion: Gamma radiation is suitable to sterilize gel containing AV powder.

Keywords: Gamma radiation, Gel, Aloe vera

(C) 2021 The Authors. Published by Innovare Academic Sciences Pvt Ltd. This is an open access article under the CC BY license (https://creativecommons.org/licenses/by/4.0/) DOI: https://dx.doi.org/10.22159/ijap.2021v13i4.41771. Journal homepage: https://innovareacademics.in/journals/index.php/ijap

Hydrogel have been used in many pharmaceutical fields such as drug delivery systems, tissue engineering, and wound dressing [1]. This is due to its structural feature and permeability, which increased its use in various fields including ophthalmology and dentistry. Furthermore, it has the ability to hold water, showing soft and rubbery-like consistency, as well as low interfacial tension [2]. Also, hydrogel is used as sterile formulation. Several sources are used for its preparation such as chitosan, cellulose, gelatine, and poloxamer [3]. Therefore, choosing the right hydrogel is needed to approach a new drug formulation [4].

Carbomer is an acrylic acid derivative, which is the most widespread type of gelling agent in the technology of medicinal formulations. These polymers are characterized by different ranges of concentrations used for many purposes including emulsification and suspending abilities, as well as rate of gel formation [5]. When dispersed in water, carbomer disperse quite well and forms viscous suspension at $\mathrm{pH}$ 2.8-3.2 [6]. Meanwhile, the mechanism of gel formation using carbomers is based on neutralization, leading to acids conversion to the corresponding salts, therefore, alkali addition is necessary $[7,8]$. The carbomer gel can be sterilized by several methods including gamma radiation [6].

This terminal radiation method has been used for many years in sterilization process of pharmaceutical products [9]. Furthermore, it is very convenient because it can be used to the final product container without any significant increase in temperature $[10,11]$. This method is suitable for products which cannot withstand heat, steam sterilization or thermosensitive solid-state drugs. This is because it is a cold method with high sterility assurance level, which makes the accuracy dose of gel easily controlled [12-14]. Therefore, this method is simpler and more environmentally friendly compared to conventional [15].

This study evaluates the physicochemical properties of aloe vera (AV) powder gel after gamma ray sterilization. AV powder was used as the material model in gel preparation because it has been widely used in medicine, including burn wound healing. Furthermore, gel from AV is often commercialized as powdered concentrate [16]. Previous study reported that the powder gel could increase wound healing process of burns [17]. Therefore, the effect of gamma radiation on physicochemical properties of gel containing AV powder including the sterility test, organoleptic, $\mathrm{pH}$, viscosity and malic acid concentration was investigated.

AV powder was purchased from PT Dwipar Loka Ayu, Indonesia. Meanwhile, Fluid Thioglycolate Medium (FTM), Soybean-Casein Digest Medium/Tryptic Soy Broth (TSB), Sabouraud Dextrose Agar (SDA) and malic acid were purchased from Sigma Aldrich. All other used chemicals were of technical grade.

Table 1: Composition of AV powder gel

\begin{tabular}{lllll}
\hline Materials & Formula (g/100g) & & \\
\cline { 2 - 5 } & I & II & III & IV \\
\hline Carbomer & 1 & 1.5 & 2.25 & 2.5 \\
AV powder & 1 & 5 & 15 & 20 \\
Glycerin & 20 & 20 & 20 & 20 \\
Triethanolamine & q. s & q. s & q.s & q. s \\
Propylparaben & 0.02 & 0.02 & 0.02 & 0.02 \\
Methylparaben & 0.18 & 0.18 & 0.18 & 0.18 \\
Sodium EDTA & 0.05 & 0.05 & 0.05 & 0.05 \\
Sodium Metabisulfite & 0.1 & 0.1 & 0.1 & 0.1 \\
Water add & 100 & 100 & 100 & 100 \\
\hline
\end{tabular}


The gel from AV powder formula is shown in table 1. Carbomer was dispersed into a mixture of glycerine and water. Furthermore, the powder and other components were dissolved in water, and added into a mixture of glycerine and distilled water. Subsequently, triethanolamine was added into the mixture and stirred until gel gormation occurred [18]. The gel sterilization was performed by storing the sample in a vial tightly capped, then sterilized by gamma ray at a dose of $25 \mathrm{kGy}$. In addition, physical stability of the gel was evaluated including the sterility test, organoleptic, $\mathrm{pH}$ and viscosity.

Malic acid as a marker compound contained in the AV powder was also evaluated by HPLC measurement. The samples were analyzed by injecting $10 \mu \mathrm{L}$ of each solution into an C18 column at $40{ }^{\circ} \mathrm{C}$. The

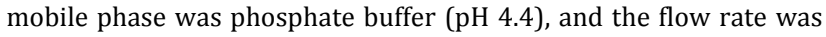
$1.25 \mathrm{ml} / \mathrm{min}$. In addition, standard solutions $(50,25,10,5,1$, and 0.5 $\mathrm{mg} / \mathrm{ml}$ ) were prepared in mobile phase, and the linear coefficient of determination (R2) value of standard solution was 0.9988 .

The data of $\mathrm{pH}$, viscosity, and malic acid concentration were presented as a mean of samples \pm standard deviation (SD) and further analyzed using the one-way analysis of variance (ANOVA) at the level of $(\mathrm{P}<0.05)$.

Carbomer was used due to widespread types of gel-forming agents. The gel formation using carbomer is based on neutralization. Therefore, the addition of neutralizing agent is needed to produce a rapid thickening of the system. Also, triethanolamine was used to neutralize the solution until gel formation was observed through ionization and hydrogen bonding of the carboxyl group. The neutralization of solutions with triethylamine produced negatively charged ions along the whole polymer chain forcing it to form extended structures in water. Furthermore, glycerine was added as humectant to prevent water loss, leading to gels formation [19]. Methylparaben and propyl paraben, ethylenediaminetetraacetic acid (EDTA) and sodium metabisulfite were used as preservatives, chelating agents and antioxidant, respectively, to prevent the degradation of compound contained in AV powder [20-22].

Gamma radiation was used to sterilize the gel because it is simpler and more environmentally-friendly compared to conventional methods [23]. Meanwhile, the dose usually applied to ensure product sterility was $25 \mathrm{kGy}$. This dose, according to Pharmacopoeia, is defined as the reference that guarantees a high sterility assurance level [9]. After sterilization, the consistency, color, and odor did not change significantly. Furthermore, the gel still had a high-viscosity and transparent properties, indicating the gamma radiation did not affect the appearance.

The sterility testing was conducted under aseptic conditions using laminar airflow (LAL). Also, micro-organisms growth (Bacillus subtilis, Candida albicans) was observed in positive control. Meanwhile in the negative control test, no micro-organisms growth was observed. This showed the media used for sterility test was suitable. This also confirmed the aseptic conditions were maintained and all equipment used for the test were sterile. In the sterility test, micro-organisms growth was not observed, indicating that gamma radiation sterilized the gel.

The result of $\mathrm{pH}$ and viscosity measurements after sterilization is shown in the fig. 3:
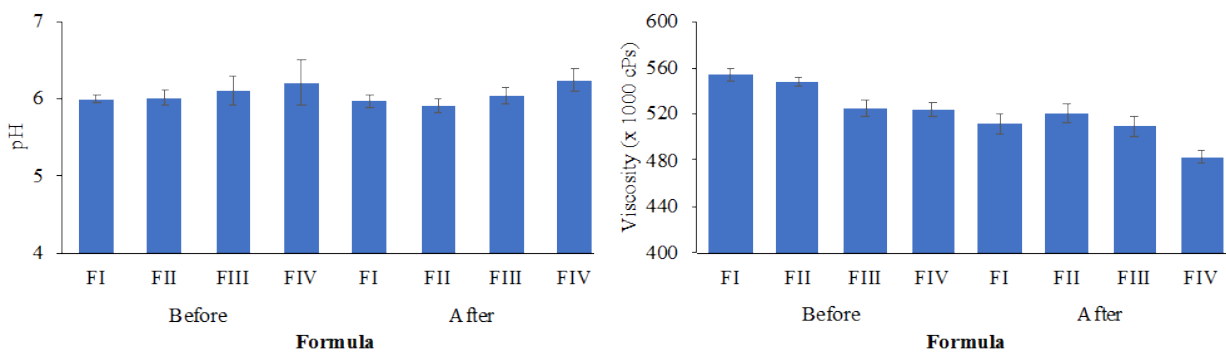

Fig. 1: The comparison of (left) $\mathrm{pH}$ and (right) viscosity of $\mathrm{AV}$ powder gel before and after sterilization (The results were calculated as mean \pm standard deviation; $\mathbf{n}=3$ )

There was no difference in $\mathrm{pH}$, while there was a decrease after sterilization using gamma ray. However, the decrease of gel viscosity was not significantly changed and still suitable for use as sterile gel preparation. This showed the gamma radiation didn't significantly affect the physical properties of the gel. Also, the gel using carbomer can be sterilized by other methods such as autoclaving as well as preparing in aseptic conditions by sterilization of each component [5]. However, the thermosensitive gel becoming fluid can induce inappropriate improvised dosing. Sterilization using high temperature could not guarantee the chemical stability of drug in gel preparation [4]. Also, the filtration is not suitable because the polymer (a large molecules) could not pass through the filter pores. This result showed gamma radiation is a suitable method to sterilize gel in the final product package without any additional process. In addition, the physical stability of sterilized gel was evaluated after 28 storage days as shown in fig. 2 and 3.

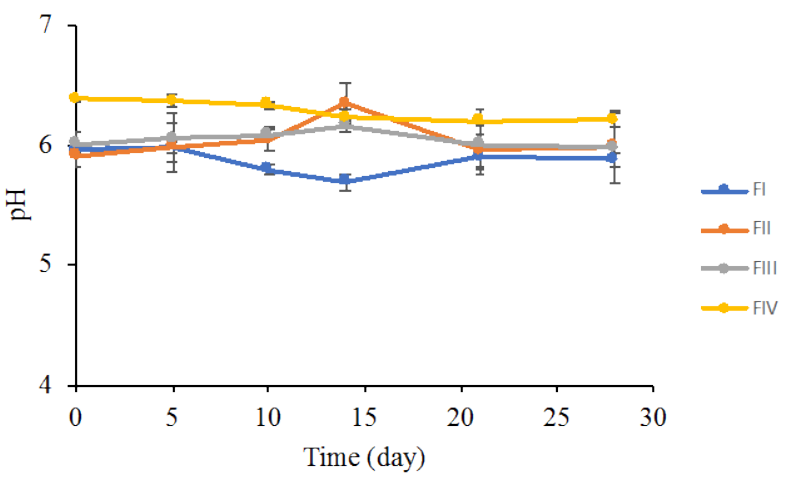

Fig. 2: $\mathrm{pH}$ of $\mathrm{AV}$ powder gel after 28 storage days (The results were calculated as mean \pm standard deviation; $\mathbf{n = 3}$ ) 


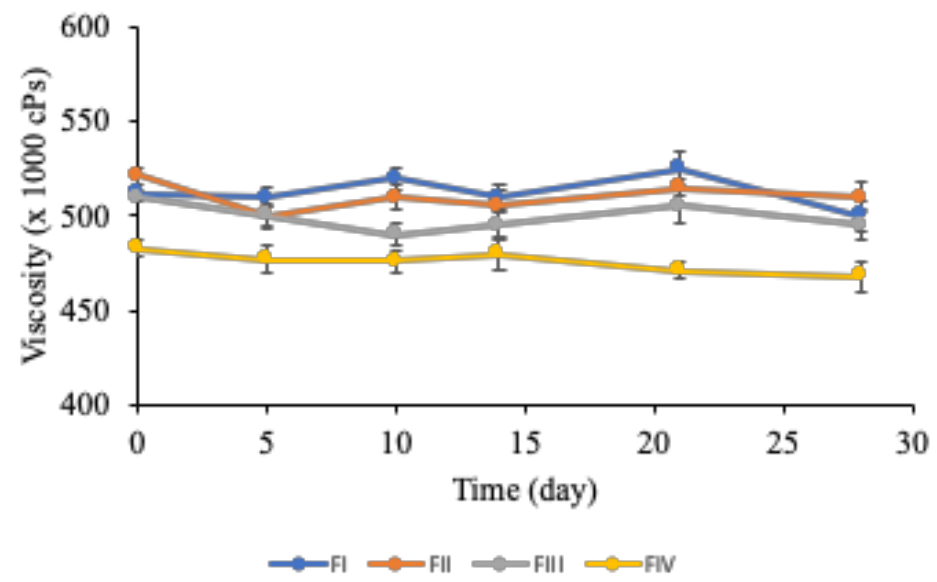

Fig. 3: The viscosity of $A V$ powder gel after 28 storage days (The results were calculated as mean \pm standard deviation; $n=3$ )

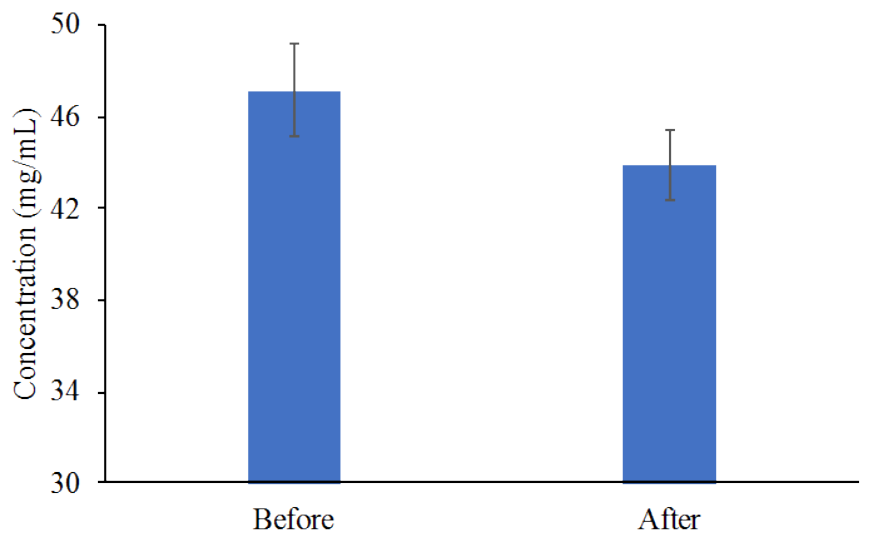

Fig. 4: The concentration of malic acid contained in AV powder gel before and after sterilization (The results were calculated as mean \pm standard deviation; $\mathrm{n}=3$ )

Based on statistical analysis, the $\mathrm{pH}$ did not change significantly even after $28 \mathrm{~d}$ with a significance value of $0.063(P>0.05)$. Furthermore, the $\mathrm{pH}$ remained within the acceptable range of topical dosage form, which is between 4.5-6.5. A similar manner was observed in the viscosity measurement. Base on statistical analysis, the viscosity did not show significant difference after 28 storage days with a significance value of $0.074(P>0.05)$.

Malic acid was used as a marker to evaluate the chemical stability of AV gel after sterilization. Previous studies reported that malic acid was used as a marker to detect adulteration and establish the authenticity of aloe gel powders $[16,25]$. In addition, the concentration in gel (FIV) after sterilization was measured as shown in fig.4.

The concentration of malic acid contained in AV powder gel before and after sterilization were $47.2 \mathrm{mg} / \mathrm{mL}$ and $43.9 \mathrm{mg} / \mathrm{mL}$, respectively. This result showed that the gamma radiation didn't significantly affect the concentration of marker compound contained in the AV powder gel. Malic acid is a natural and essential component of plant photosynthesis from aloe gel [16]. This acid was considered an indicator of freshness and gel quality. In fact, the concentration was commonly observed in the range of $11.1 \%$ and $40.4 \%$ [26]. The lower value of malic acid in liquid fraction can be used as indicators of bacterial degradation in the sample [27]. Previous study also reported that malic acid has been shown to have antimicrobial activity [28]. Meanwhile, other compounds such as glucose and some phenolic compounds can be used as markers [25, $29,30]$. The concentration of organic acids including citric, lactic and succinic acids was higher than malic in the commercial aloe gel powders. The measurement of these compounds especially those with a potential to increase wound healing process is needed as further investigation. This is to fully understand the relationship between sterilization by gamma radiation and the wound healing process from $\mathrm{AV}$ powder gel.

This study investigated the physicochemical properties of gel containing $A V$ powder after sterilization with gamma radiation. The sterility test showed there was no growth of micro-organisms, while physical properties of the gel, as well as its marker compound showed no significant changes. Therefore, this study provided fundamental insight that gamma radiation is a suitable method to sterilize $\mathrm{AV}$ powder gel in the final product package.

\section{FUNDING}

Nil

\section{AUTHORS CONTRIBUTIONS}

All the authors have contributed equally.

\section{CONFLICT OF INTERESTS}

\section{Declared none}

\section{REFERENCES}

1. Ahmed EM. Hydrogel: preparation, characterization, and applications: a review. J Adv Res 2015;6:105-21.

2. Lugao AB, Rogero SO, Malmonge SM. Rheological behaviour of irradiated wound dressing poly (vinyl pyrrolidone) hydrogels. Radiat Phys Chem 2002;63:543-6.

3. Chatterjee S, Hui PC, Kan CW. Thermoresponsive hydrogels and their biomedical applications: Special insight into their 
applications in textile based transdermal therapy. Polymers 2018;10:480.

4. Zanon D, Volpato C, Addobbati R, Loiacono S, Maestro A, Barbi $\mathrm{E}$, et al. Stability of a novel lidocaine, adrenaline and tetracaine sterile thermosensitive gel: a ready-to-use formulation. Eur J Pharm Sci 2019;136:104962.

5. Anurova MN, Bakhrushina EO, Demina NB. Review of contemporary gel-forming agents in the technology of dosage forms. Pharm Chem J 2015;49:627-34.

6. Rabiskova M, Sedlakova M, Vitkova M, Kuna M. Carbomers and their use in pharmaceutical technology. Ceska Slov Farm Ces Slov Far Cesk Farm Cesk Farm 2004;53:300-3.

7. Gad SC. Pharmaceutical manufacturing handbook production and processes north carolina. New Jersey: John Wiley and Sons Inc; 2008.

8. Niazi SK. Handbook of pharmaceutical manu-facturing formulations. Part II. Formulations of Semisolid Drugs. Florida: CRC Press LLC; 2004.

9. Silindir M, Ozer AY. Sterilization methods and the comparison of E-beam sterilization with gamma radiation sterilization. Fabad J Pharm Sci 2009;34:43.

10. Reid BD. Gamma processing technology: an alternative technology for terminal sterilization of parenterals. PDA J Pharm Sci Tech 1995;49:83-9.

11. Olguner G, Ozer AY. Radyasyonla sterilizasyon II: Ilacların radyasyonla sterilizasyonu. FABAD J Pharm Sci 2000;25:53-73.

12. Higashi N, Yokota H, Hiraki S, Ozaki Y. Direct determination of peracetic acid, hydrogen peroxide, and acetic acid in disinfectant solutions by far-ultraviolet absorbtion spectroscopy. Anal Chem 2005;77:2272-7.

13. Maquille A, Slegers C, Habib JL, Tilquin B. Electron beam and gamma radiolysis of solid-state metoclopramide. Pharm Res 2006;23:1343-9.

14. Boyd C. E-beam sterilizes the industry. J Student Res 2002;1:39-43.

15. Huq T, Khan A, Dussault D, Salmieri S, Khan RA, Lacroix M. Effect of gamma radiation on the physico-chemical properties of alginatebased films and beads. Radiat Phys Chem 2012;81:945-8

16. Bozzi A, Perrin C, Austin S, Vera FA. Quality and authenticity of commercial aloe vera gel powders. Food Chem 2007;103:22-30.

17. Budiman A, Khoerunnisa R, Qoriah TA. Wound-healing test of Piper betle leaf extract and aloe vera in gel preparation. Int J Appl Pharm 2018;10:86-91.
18. Islam MT, Rodriguez Hornedo N, Ciotti S, Ackermann C. Rheological characterization of topical carbomer gels neutralized to different pH. Pharm Res 2004;21:1192-9.

19. Mukherjee D, Banthia AK. Preparation of adrenochrome hydrogel patch, gel, ointment, and the comparison of their blood coagulating and wound healing capability. Mater Manuf Process 2006;21:297-301.

20. Patil PM, Wankhede SB, Chaudhari PD. Stability-indicating HPTLC method for simultaneous determination of Ketoprofen, methyl paraben and propyl paraben in gel formulation. J Pharm Res 2013;6:945-53.

21. Dotto SR, Travassos RMC, De Oliveira EPM, de Lima Machado ME, Martins JL. Evaluation of ethylenediaminetetraacetic acid (EDTA) solution and gel for smear layer removal. Aust Dent J 2007;33:62-5.

22. Maia AM, Baby AR, Pinto CA, Yasaka WJ, Suenaga E, Kaneko TM Velasco MVR. Influence of sodium metabisulfite and glutathione on the stability of vitamin $\mathrm{C}$ in $\mathrm{O} / \mathrm{W}$ emulsion and extemporaneous aqueous gel. Int J Pharm 2006;322:130-5.

23. Byun EH, Kim JH, Sung NY, Choi JI, Lim ST, Kim KH, et al. Effects of gamma irradiation on the physical and structural properties of $\beta$-glucan. Radiat Phys Chem 2008;77:781-6.

24. Ajji Z, Othman I, Rosiak JM. Production of hydrogel wound dressings using gamma radiation. Nucl Instrum Methods Phys Res B 2005;229:375-80.

25. Kim KH, Lee JG, Gyuun D, Kim MK, Park JH, Shin YG, et al. The development of a new method to detect the adulteration of commercial aloe gel powders. Arch Pharm Res 1998;21:514-20.

26. Jiao P, Jia Q, Randel G, Diehl B, Weaver S, Milligan G. Quantitative ${ }^{1} \mathrm{H}$-NMR spectrometry method for quality control of Aloe vera products. J AOAC Int 2010;93:842-8.

27. Garcia MJ, Zuniga M, Kobayashi H. Energy production from Lmalic acid degradation and protection against acidic external $\mathrm{pH}$ in lactobacillus plantarum CECT 220. Microbiology 1992;138:2519-24.

28. Raybaudi Massilia RM, Mosqueda Melgar J, Martin Belloso 0. Edible alginate-based coating as carrier of antimicrobials to improve shelf-life and safety of fresh-cut melon. Int J Food Microbiol 2008;121:313-27.

29. Pelley RP, Wang YT, Waller TA. Current status of quality control of Aloe barbadensis extracts. Seifen Ole Fette Wachse 1993;119:255.

30. Kumar S, Yadav M, Yadav A, Yadav JP. Molecular assessment of genetic diversity in Indian accessions of Aloe vera using SSR marker. Int J Pharm Pharm Sci 2015;7:149-54. 